\title{
Do We Really Want Sports Public Relations to Return to Normal?
}

\section{Christie M. Kleinmann}

Belmont University

\begin{abstract}
Sports public relations has long been used to promote the big game and highlight key players. Then, the coronavirus crisis halted sports, and the constant stream of public relations content fell silent. There was no game to hype, no sports moment to celebrate. This essay is about the public relations lessons learned during the pandemic. It discusses how sports public relations prior to COVID-19 often valued relational breadth over depth. As a result, sports public relations operated at a superficial level of momentary engagements sustained by creative content rather than the deeper relational connections that public relations purport. The essay then illustrates how COVID-19 cultivated opportunities for relational breadth and depth to grow between players and fans. Finally, the essay questions if we really want sports public relations to return to normal or if sports public relations professionals should incorporate these lessons into sustainable, postpandemic public relations practice.
\end{abstract}

Keywords: relationships, social penetration theory, symmetrical communication

Sports fans, athletes, and sports personnel have speculated on how and when sports and its functions will return to normal, but is normal what we really want? Sports have long used the function of public relations to promote the big game and highlight key players. Before COVID-19, we thought sports public relations fostered real relationships, but we confused a retweet or comment with conversation. We mislabeled game-day engagement as a relationship, and we mistook the superficial for an authentic connection. In our defense, this was all we had ever known. We were accustomed to a steady stream of creative content from sports public relations professionals; yet, these were mere shadows masquerading as reality.

We found reality, or rather, reality found us, with COVID-19 and the subsequent suspension of sports. For the first time, the stream of creative public relations content fell silent. There was no game to hype and no sports moment to celebrate. There were no sports, but there were still sports people. This essay is about those people and the experience that moved us-league personnel, athletes, fans-from the shadows of superficiality to the light of authentic connection. To do

The author (christie.kleinmann@belmont.edu) is with the Dept. of Public Relations, College of Liberal Arts \& Social Sciences, Belmont University, Nashville, TN, USA. 
so, this essay first considers the practice of sports public relations by its usage of the four models of public relations. Then, using the lens of social penetration theory, it suggests that sports public relations has too often valued breadth, fostering superficial rather than authentic relationships. Finally, the essay illustrates how COVID-19 provided the opportunity for sports public relations to transition from a superficial practice and foster a deeper relationship between athletes and fans.

\section{Public Relations Models}

Public relations goes by many names-publicity, media relations, game-day events, crisis communication, and social media content creator, to name a few. Despite the different terminology, these share a common practice. Grunig and Hunt (1984) conceptualized this practice as the four models of public relations: press agentry/publicity, public information, asymmetrical communication, and symmetrical communication. They suggested that these four models progress in sophistication and effectiveness. Press agentry/publicity and public information represent the two oldest and lowest forms of public relations. Both utilize a one-way communication model designed to push information out to key groups of people. Press agentry/publicity seeks to garner attention through events and publicity stunts, while public information uses news media to disseminate information. Of these lower models, public information is deemed more credible because information is vetted through a third part, the news media.

The final two public relations models, asymmetrical communication and symmetrical communication, are considered more effective than their counterparts. The asymmetrical communication model utilizes research through limited twoway communication in order to ascertain the effectiveness of a persuasive strategy on select stakeholders. In contrast, the symmetrical communication model fosters two-way communication in order to develop and maintain relationships. Grunig and Hunt (1984) conceived symmetrical communication as the optimal form of public relations. Using this model, public relations professionals are said to facilitate meaningful relationships that mutually benefit both the organization and its stakeholders.

Despite its value, public relations professionals most often practice at the lower levels of the model (Grunig \& Grunig, 1992). Sports public relations professionals have long used publicity events to increase game attendance and enhance fan involvement. Fireworks displays, game giveaways, mascot memes, clever tweets, and promotional videos are all common publicity methods designed to redirect a public's short attention span back to the team and its athletes. The public information model also focuses the public's attention on the sport organization and its athletes by utilizing news media. This is especially true in sports. Sports and news media have a long, historical connection so intertwined that scholars have combined the terms into one, mediasport. Mediasport suggests that media and sport share a symbiotic relationship, each needing the other to survive (Wenner, 1998). In sports public relations, the public information model utilizes mediasport to disseminate information through news media. By doing so, public relations is able to distribute key organizational messages as "news," using media 
as a credible third party. Pregame features, in-game interviews, and postgame news conferences offer key venues to inform fans about an array of sports topics and correct misinformation when necessary. Limited by their one-way communication design, however, these models are unable to develop the relational connection between the organization and its fans that sports public relations promises. The symmetrical public relations model offers a solution. Its focus on two-way communication suggests a potential venue for fans and sports organizations to communicate with one another.

Savvy public relations professionals have found ways to converse with fans on a breadth of topics. From great game moments and season predictions to athlete highlights - the potential for creative content is vast. The issue is that the conversation is often broad, but rarely deep. Even "behind-the-scenes" communications are rarely more than a broader look at an athlete's public persona. Furthermore, the symmetrical model is inconsistently applied. While some athletes may be willing to share their personal information and opinions, communication channels often close abruptly at the sign of crisis. For example, Houston Astros player Alex Bregman became a social media hermit, locking the comment section on his Instagram following the Astros sign-stealing scandal (Lee, 2020a). As a result, the breadth of two-way communication is ultimately determined by the sports organization or the athlete.

While breadth determines the width of a conversation, depth determines the mutual understanding between relational parties. Breadth is the various facets of life. Depth is the personal details connected to each of these facets. To achieve the symmetrical communication model, depth is critical.

\section{Breadth and Depth of Social Penetration Theory}

Altman and Taylor's (1973) social penetration theory explains how breadth and depth form a relationship, conceiving a relationship as the layers of an onion. The outer layers of the onion represent a superficial level of a relationship, characterized by easily accessible information about a person. The relationship deepens by increasingly intimate relational disclosure, revealing an individual's thoughts and feelings. This self-disclosure allows relational partners to move below the public persona and understand the inner self. According to Altman and Taylor (1973), most relationships remain at a superficial level, communicating about likes and dislikes or sharing personal opinions.

Prior to the coronavirus pandemic, most symmetrical public relations achieved relationships only at this superficial level. Sports public relations professionals offered a wide array of information about sports and its heroes. On the field, fans could obtain live game stats, injury report updates, "behind-the-scenes" strategy, and even "eavesdrop" as players reflected on critical game moments. Off the field, fans learned players' favorite food or sports hero and their quirky habits. Athletes would often share likes and dislikes and even offer their opinion on select topics. Despite these efforts, it amounted to a superficial relationship founded on shallow content about a very public persona.

According to interpersonal communication scholars, with each additional disclosure between relational partners, the true self or personality is revealed to one 
another (Altman \& Taylor, 1973). The public persona has been replaced with the core self. Once achieved, these sustainable relationships move up and down from superficiality to greater depth. This up and down movement of relational disclosure resembles the give-and-take dynamic of mutually beneficial relationships in symmetrical communication.

At first glance, social media content promises the relational depth needed to achieve symmetrical communication. Its focus on engagement creates the feel of conversation. Fans respond to a player tweet and occasionally receive a return response from the athlete or sports organization. Content creators generate socially relevant content that garners impressive engagement metrics. While these cover a breadth of content, their disclosures reveal little, maintaining a superficial level. In a recent interview, one sports public relations professional explained this by distinguishing between creative content and connective content. Creative content extends the sports experience to the second screen. Fans relive great sports moments and share those moments with others through social media. Yet, these are moments of engagement, not relationships. According to this sports public relations professional, COVID-19 necessitated a shift to connective content that went deeper than a sports moment-because there were no traditional sports moments to share (C. Danoff, personal interview, May 15, 2020). Sports public relations facilitated this shift to connective content in three key ways: by the shared experience and subsequent self-disclosure of athletes and fans, by the shedding of athletes' public persona, and by athletes and sports personnel sharing their private spaces of home and family.

\section{Shared Experience and Self-Disclosure}

Following the suspension of sports, creative content initially fell silent. Granted, many sought to extend previous game experiences through the replay of old sports memories. Yet, as one sports public relations professional explained, richer content was possible due to the shared coronavirus experience of athletes and fans. When people have similar meaningful experiences, they share greater commonality in their disclosures, causing the relationship to grow deeper (C. Danoff, personal interview, May 15, 2020).

Thanks to COVID-19, athletes and fans had similar living constraints, with the joys and frustrations of quarantine living. For example, in a Zoom call, three National Hockey League players discussed how they spent their time during quarantine. Nashville Predators captain Roman Josi and Chicago Blackhawks captain Jonathan Toews revealed how quiet things were and their challenge to stay busy, while St. Louis Blues captain Alex Pietrangelo laughingly bemoaned how his day was dictated by the needs of his two young children. Mary Clarke on FanSided said that the Zoom calls showed that "NHL players are just like us" (Clarke, 2020, par. 1). Thus, this self-disclosure beyond the public persona deepened the fan-athlete relationship as fans related to similar home quarantine experiences of isolation or living with children during the pandemic.

COVID-19 also created an opportunity for shared experience between players and fans as they shared their disappointment over altered sports seasons and their fear 
for health and safety. For example, Major League Baseball's \#openingdayathome created a full day of at-home festivities for baseball fans to relive one win for each ballclub. The event was designed to create a digital community among baseball fans and players who were separated physically, but it also created deeper disclosure, as athletes and fans shared favorite memories of previous opening days, as well as their disappointment for this season. Dodgers player Enrique Hernandez wrote a letter to baseball, expressing what he missed about the game, and Chris Archer responded to a fan's tweet about his kids creating what they believed would have happened in the Pirates home opener at Tampa Bay. Many athletes expressed their gratitude to fans and conveyed messages of connection with the hashtag \#OneTeam (Lee, 2020b).

According to social penetration theory, the disclosure of shared fears can further deepen a relationship. Both Nationals pitcher Sean Doolittle and Angels center fielder Mike Trout expressed their fear of the resumption of the Major League Baseball (MLB) season. Doolittle posted a series of tweets outlining his concern for the safety of players, families, staff, and stadium personnel, along with his personal concern for the safety of his wife (Baer, 2020). Similarly, Trout expressed concern about the health and safety of his pregnant wife (Wittenmyer, 2020). Their fears for personal and family safety echo the same fears of sports fans. When fears such as these are shared between relational partners, mutual understanding inherent in symmetrical communication deepens, and the relationship becomes more authentic.

\section{Public Persona and True Personality}

As self-disclosure increases in symmetrical communication, relational partners can begin to see the "true personality" that lies beneath the public persona (Altman \& Taylor, 1973). During COVID-19, sports public relations professionals in the National Basketball Association (NBA) and MLB sought to foster this disclosure by showing athletes outside of sports. NBA player Cody Zeller tweeted his efforts at learning to cook and playing guitar, while others showed themselves doing "normal" things while in quarantine, such as MLB player Jeff McNeil tweeting his Toy Story Monopoly win and Chicago Cubs catcher Willson Contreras playing catch at home with his brother (Cohen, 2020).

In addition to showing athletes outside of sports, several sports public relations professionals invited fans to engage with athletes. L.A. Dodgers fans were invited to join Dodgers pitcher Clayton Kershaw and his family in "A Day in the Life of the Kershaws," while Orioles fans could share a nighttime story with first baseman Chris Davis and his family (Gonzalez \& Lee, 2020). Still other athletes invited fans to interact in real time through online gaming. Blake Snell with the Tampa Bay Rays played video games with other athletes, allowing fans a look beyond his baseball persona (Lee, 2020a). Marco Gonzales with the Seattle Mariners said that these nonsports connections were important ways for people to get to know athletes as people, while Dodgers chief marketing officer Lon Rosen noted that these opportunities for engagement were an intentional effort to connect fans and players during the pandemic (Gonzalez \& Lee, 2020). The result was a rare glimpse past the public persona into the true personality of athletes. 


\section{Private Spaces}

Finally, COVID-19 necessitated a sharing of private space, such as the living room or kitchen. Just consider the attention a person's bookshelves received during a Zoom call. They were not simply the background for a virtual conversation; they were scrutinized as a window into a person's inner core (Heathcote, 2020). Relational disclosure then comes in the form of space. Qualitative researchers have long understood the power of private space to achieve a deeper level of understanding (Corbin \& Strauss, 2014). COVID-19 required us to share these private spaces, and in doing so, often conveyed more intimate details than our words ever could. The recent National Football League (NFL) draft illustrates how space can facilitate authentic connection. This year fans were greeted from living room couches rather than red carpets, and draftees celebrated with intimate family rather than a room of strangers. Sports writer Dan Wetzel (2020) recognized this authentic connection, saying that the NFL draft "found a way to connect the public and its favorite sport in a way no marketing campaign, fireworks display, red carpet or Roger Goodell bro hug ever could" (par. 13). By sharing this private space, athletes and sports personnel deepened their level of disclosure with sports fans.

In conclusion, the COVID-19 pandemic created many ills for society and revealed some hard truths about deficiencies and shortcomings in our systems and processes, even in sports public relations. Despite a wealth of creative content, sports public relations professionals often fell short of the symmetrical relationships they purport to build. These relationships often had breadth, but only superficial depth. Yet, COVID-19 also produced some good. It cultivated opportunities for players and fans to build symmetrical relationships. Through shared experiences and relational disclosures, sports public relations professionals moved players and fans beyond the superficial and encouraged the authentic connections that foster symmetrical relationships. True, COVID-19 leaves unprecedented challenges in its wake, but this essay is not about those challenges. It is about human connections and the relational processes that facilitate them. And it leaves us with a question: Now that we have experienced the beginning of authentic connection, do we really want sports public relations to return to normal? Or, can sports public relations professionals incorporate the lessons of this moment into postpandemic sports public relations practice?

\section{References}

Altman, L., \& Taylor, D. (1973). Social penetration theory. New York, NY: Holt, Rinehart \& Winston.

Baer, B. (2020, May 11). Sean Doolittle has some thoughts about MLB's proposal to restart season. NBC Sports. Retrieved from https://mlb.nbcsports.com/2020/05/11/seandoolittle-has-some-thoughts-about-mlbs-proposal-to-restart-season/?partner=Yahoo

Clarke, M. (2020, April). Hilarious Zoom calls between top NHL players is levity we need right now. Fansided. Retrieved from https://fansided.com/2020/03/26/nhl-zoom-callsgiroux-crosby-ovechkin-subban/

Cohen, K. (2020, March 17). Here's what athletes are doing around the globe amid the coronavirus outbreak. ESPN. Retrieved from https://www.espn.com/espn/story/_/id/ 28913914/here-athletes-doing-globe-amid-coronavirus-outbreak 
Corbin, J., \& Strauss, A. (2014). Basics of qualitative research: Techniques and procedures for developing grounded theory (4th ed.). Newbury Park, CA: SAGE Publications, Inc.

Gonzalez, A., \& Lee, J. (2020, May 25). How the coronavirus is forever changing the way MLB connects to fans. ESPN. Retrieved from https://www.espn.com/mlb/story/_/id/ 29161137/how-coronavirus-forever-changing-way-mlb-connects-fans

Grunig, J.E., \& Grunig, L.A. (1992). Models of public relations and communication. In J.E. Grunig (Ed.), Excellence in public relations and communication management (pp. 285-326). Hillsdale, NJ: Lawrence Erlbaum Associates, Inc.

Grunig, J.E., \& Hunt, T. (1984). Managing public relations. New York, NY: Holt, Rinehart $\&$ Winston.

Heathcote, E. (2020, April 25). When bookshelves are more informative than the books. Financial Times. Retrieved from https://www.ft.com/content/57284374-83b3-11eab6e9-a94cffd1d9bf

Lee, J. (2020a, March 23). Ten MLB players to follow on social media during the coronavirus shutdown. ESPN. Retrieved from https://www.espn.com/mlb/story/_/id/ 28925713/ten-mlb-players-follow-social-media-coronavirus-shutdown

Lee, J. (2020b, March 26). \#OpeningDayAtHome: MLB stars share thoughts with fans on day baseball didn't begin. ESPN. Retrieved from https://www.espn.com/mlb/story/_ id/28959272/mlb-stars-share-thoughts-fans-opening-day

Wenner, L. (1998). Playing the mediasport game. In L. Wenner (ed.), MediaSport (pp. 313). London, UK: Routledge.

Wetzel, D. (2020, April 26). Here's hoping the 2020 NFL draft serves as a model for the future. Here's guessing it won't. Yahoo! Sports. Retrieved from https://sports.yahoo. com/heres-hoping-the-2020-nfl-draft-serves-as-a-model-for-the-future-heres-guessingit-wont-164123859.html

Wittenmyer, G. (2020, May 22). Why Cubs, MLB might face 2020 season without key players and what it means. NBC Sports Chicago. Retrieved from https://sports.yahoo. com/why-cubs-mlb-might-face-024139112.html 